\title{
Biomechanical comparison of anatomical plating systems for comminuted distal humeral fractures
}

\author{
Patrick A. Varady ${ }^{1,2}$. Christian von Rüden ${ }^{1,2,3}$ - Markus Greinwald ${ }^{1,2}$. \\ Sven Hungerer ${ }^{1,2,3} \cdot$ Robert Pätzold ${ }^{1,2,3}$ • Peter Augat ${ }^{1,2}$
}

Received: 16 December 2016 / Accepted: 10 March 2017 /Published online: 27 March 2017

(C) The Author(s) 2017. This article is published with open access at Springerlink.com

\begin{abstract}
Purpose Six different mono-axial and poly-axial distal humeral plating systems with an anatomical plate design were compared. The aim of the biomechanical tests was to examine differences regarding system stiffness, median fatigue limit, and failure mechanisms.

Methods Different configurations of two double plate fixation systems by two manufacturers for the treatment of complex distal humeral fractures (AO/OTA type C2.3) were biomechanically tested in a physiologically relevant setup.

Results The $180^{\circ}$ Stryker configuration presented itself as the system with the highest stiffness, being significantly stiffer $(p$ $<0.001$ ) than every system other than the poly-axial $180^{\circ}$ aap system $(\mathrm{p}=0.378)$. For the median fatigue limit the $180^{\circ}$ Stryker and poly-axial aap systems were ranked first and second. The failure mechanism for all $90^{\circ}$ systems was a fatigue breakage of the posterolateral plate. The $180^{\circ}$ aap systems demonstrated breakage of the most distal screws of the lateral plate. The $180^{\circ}$ Stryker system demonstrated screw breakage on both the medial and lateral plates.

Discussion Breakage of the posterolateral plate as a failure mechanism for the $90^{\circ}$ systems was expected. The $180^{\circ}$
\end{abstract}

Patrick A. Varady and Christian von Rüden contributed equally to this work.

Patrick A. Varady

p.varady@ibmb.tu-bs.de

1 Institute of Biomechanics, Paracelsus Medical University, Salzburg, Austria

2 Institute of Biomechanics, Trauma Centre Murnau, Professor Küntscher Str. 8, 82418 Murnau, Germany

3 Department of Trauma Surgery, Trauma Centre Murnau, Professor Küntscher Str. 8, 82418 Murnau, Germany systems demonstrated a higher stiffness compared to the $90^{\circ}$ constructs for the axial loading. In conclusion, both poly-axial anatomical plating systems provide sufficient stability in this scenario, and the $180^{\circ}$ configurations demonstrated superior stiffness.

Keywords Anatomical poly-axial plate $\cdot$ Distal humeral fracture $\cdot$ Failure mechanism $\cdot$ Fatigue limit $\cdot$ System stiffness

\section{Introduction}

Comminuted distal humeral fractures remain a challenge in trauma surgery [1]. There is insufficient evidence from randomized controlled trials that investigate which surgical interventions are the most appropriate for the surgical treatment of different types of distal humeral fractures [2]. The current gold standard for surgical treatment of intra-articular distal humeral fractures is open reduction and internal fixation with plates and/or screws [3]. In earlier studies, locked plating configurations demonstrated significantly better performance than nonlocked plating configurations, independently of their orientation [4]. The fixation methods evolved into the present third generation of locking plates which include anatomical plate design and poly-axial locking screws. These features aim at rigid stability to allow early mobilization as well as adequate stiffness to stimulate fracture healing [5]. The preferred plating techniques for comminuted distal humeral fractures include the Mayo clinic configuration $\left(180^{\circ}\right.$ between plates) with parallel plate fixation and medial and lateral plate positioning as well as the AO/ASIF configuration $\left(90^{\circ}\right.$ angle between plates) with perpendicular plate fixation and medial and postero-lateral plate positioning [3, 6-9]. Parallel orientation of the plates seemed biomechanically superior [10], but for the translation to the clinical setting the soft tissue envelope and 
Fig. 1 Examples for the $90^{\circ}$ (left) and $180^{\circ}$ (right) configuration and fracture design

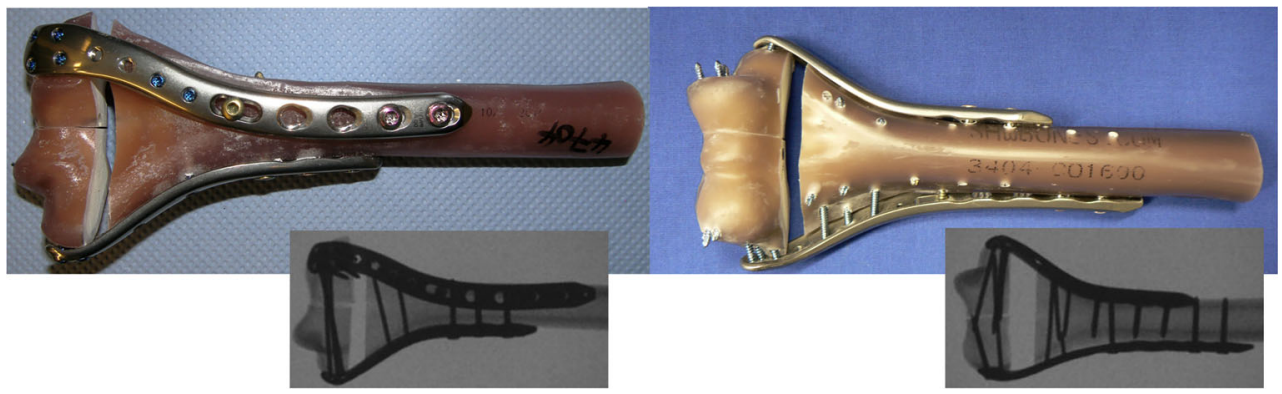

exposure of the distal humerus must be taken into consideration [4]. Hence, under some circumstances the $90^{\circ}$ angle configuration might be preferable. Moreover, recent literature indicated that fixed-angle screw trajectories can make it difficult to place screws of correct length in this anatomically circumscribed region [11]. A main focus of this study is to give surgeons an idea about the biomechanical characteristics of different implant systems and configurations, especially to create an understanding of the stability of the different configurations. Subsequently, this should help the surgeon to have another parameter to include in his or her decision on which configuration to use during surgery.

In the present study the two preferred application positions (parallel and perpendicular fixation) combined with monoaxial or poly-axial screws were compared biomechanically regarding system stiffness, median fatigue limit, and failure mechanisms. We hypothesized that different fixation configurations of the different plate designs would lead to different mechanical stability of complex distal humeral fractures.

\section{Materials and methods}

The choice of load application $[12,13]$ as well as testing procedures [14] were based on previous studies and are briefly summarized below.

\section{Implant types}

Osteosynthesis systems for the distal humerus with poly-axial locking screws (Stryker Corporation, Kalamazoo, Michigan,

Table 1 Implant specifications of the testing sample

\begin{tabular}{lll}
\hline Manufacturer & Type & Part number \\
\hline Stryker & $180^{\circ}$, poly-axial & 629286,629206 \\
& $90^{\circ}$, poly-axial & 629286,629048 \\
aap & $180^{\circ}$, mono-axial & PH 3522-03-2, PH 3542-05-2 \\
& $90^{\circ}$, mono-axial & PH 3521-03-2, PH 3531-05-2 \\
& $180^{\circ}$, poly-axial & PH 3524-03-2, PH 3544-05-2 \\
& $90^{\circ}$, poly-axial & PH 3524-03-2, PH 3534-05-2 \\
& &
\end{tabular}

U.S.A.) and with mono and poly-axial locking screws (aap Implantate AG, Berlin, Germany) were tested in two different configurations (Fig. 1): a combination of medial and lateral plate $\left(180^{\circ}\right)$ and a combination of medial and posterior plate $\left(90^{\circ}\right)$. Plating systems varied in the locking mechanisms of the screws, i.e., mono-axial or poly-axial systems, resulting in six groups (Table 1).

\section{Fracture configuration}

Three senior physicians were instructed to create an AO/OTA type C2.3 fracture (intraarticular fracture site and a metaphyseal comminution area) on Large Left 4 th Generation Composite Humerus (Item \#3404, Sawbones Europe AB, Malmö, Sweden). The comminution zone was created by removal of a $6 \mathrm{~mm}$ thick bone piece in the transversal plane, starting $15 \mathrm{~mm}$ proximal of the distal joint axis. A second osteotomy was performed with a $0.5 \mathrm{~mm}$ saw from the deepest point of the trochlea humeri meeting the proximal fracture gap. Afterwards, the surgeons would attach the plates

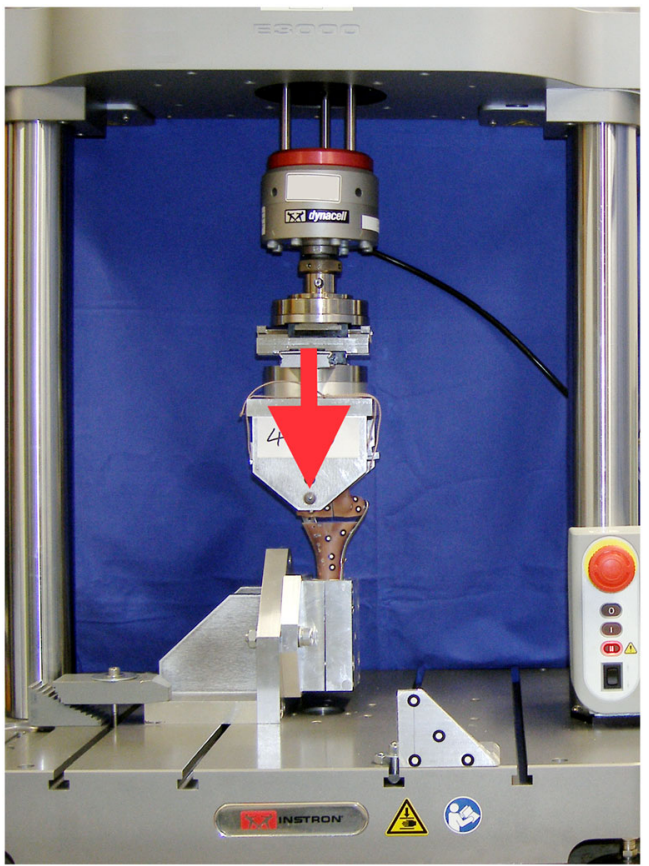

Fig. 2 Test setup with a specimen clamped in the testing machine (red arrow indicates loading direction) 


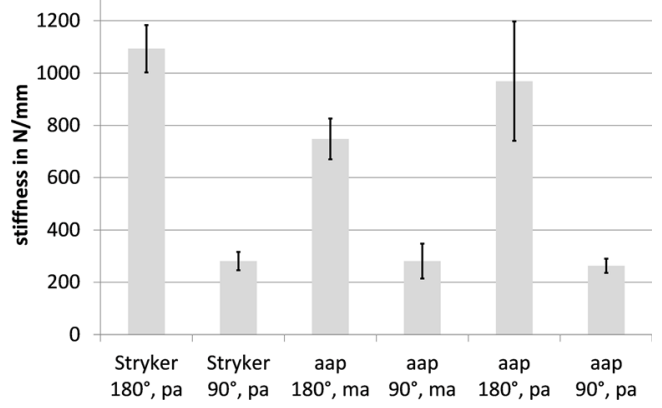

Fig. 3 Mean (with SD) stiffness in $\mathrm{N} / \mathrm{mm}$ for the six groups

to create the correct osteosynthesis. Implants were used according to manufacturer's instructions: For the Stryker system $2.7 \mathrm{~mm}$ screws were utilized and for the aap system $2.5 \mathrm{~mm}$, $2.7 \mathrm{~mm}$, and $3.5 \mathrm{~mm}$ screws were used. For the poly-axial implants surgeons were instructed to use the screws in a $0^{\circ}$ angle. The composite humeri were cut off $190 \mathrm{~mm}$ from their proximal end for fixation in the clamping device.

\section{Test setup and parameters}

For each of the six tested groups, a two-piece mold was created out of polymethylmethacrylate (RENCAST FC 53, Huntsman Advanced Materials, Bad Säckingen, Germany) where only the bone was embedded, but not the plates or screws. The specimens were then clamped in a testing machine (INSTRON E3000/8874, INSTRON GmbH, Darmstadt, Germany; Fig. 2) which was equipped with a $10 \mathrm{kN}$ load cell, with accuracy class 0.5 (DIN EN ISO 75001). Specimens were loaded at the elbow joint in a $5^{\circ}$ flexion angle which represents an extended position of the arm. Compressive loading was induced by using a compensator with an eccentric centre of rotation. By eccentric loading a force distribution of $60 \%$ on the humero-radial joint and $40 \%$ on the humero-ulnar joint could be realized [13, 15]. Stiffnesses of the specimens were assessed by using at least three specimens from each group that were loaded to $300 \mathrm{~N}$ three times for setting and once for stiffness determination. One specimen in each group was further loaded until failure in order to estimate the system yield strength $\left(R_{p 0.2}\right)$ for the starting point of the cyclic fatigue testing. Median fatigue limit
(MFL) testing was based on ASTM STP 731 [16], a technical standard for fatigue tests by the American Society for Testing and Materials, and was conducted according to our previous study [14] with a run out criterion of 250,000 cycles as an approximate number of movements during three months after surgery. Failure criteria for destructive and MFL testing was bone, plate or screw failure or a displacement more than 4 $\mathrm{mm}$. MFL tests started with $50 \%$ of the previously estimated systems yield strengths $\left(R_{p 0.2}\right)$, and loads were then either increased (run out) or decreased (failure) by $10 \% R_{p 0.2}$ for the next specimen of a group.

\section{Outcome parameters and data analyses}

MFL was calculated according to ASTM STP 731 [16]. The measured stiffnesses were in every case corrected with testing machines' stiffnesses by assuming a serial connection of springs (machine and specimen). Comparison of stiffnesses was performed in IBM SPSS Statistics 19 (IBM Corp, Armonk, NY, U.S.A.). Significance level was set to $\alpha=$ 0.05 . For stiffness comparison of the different implant systems a three-way (manufacturer, configuration, poly-/mono-axial) analysis of variance was performed. Individual stiffnesses were compared by student's t-tests (Bonferroni adjusted: $\alpha^{*}$ $=0.05 / 15=0.003$ ). MFLs were compared by one-way (implant system) ANOVA and post-hoc Tukey's HSD.

\section{Results}

The absolute differences among the individual groups and their respective post hoc p-values are depicted in Fig. 3 and Table 2 for the stiffness and Fig. 4 and Table 3 for the median fatigue limit. The three-way ANOVA demonstrated that the main effect configuration had a significant effect $(p<0.001)$ on stiffness, with the $180^{\circ}$ configurations demonstrating three times higher stiffness compared to the $90^{\circ}$ configurations (Fig. 3). For the main effect of manufacturer, no differences were found for $90^{\circ}$ configuration but for the $180^{\circ}$ configuration the Stryker constructs were significantly stiffer ( $46 \%$ and $13 \%)$ compared to both aap constructs $(p<0.01)$. Comparing
Table 2 Post hoc comparison of construct stiffness for all individual groups

\begin{tabular}{|c|c|c|c|c|c|c|}
\hline & $\begin{array}{l}\text { Stryker } 180^{\circ} \text {, } \\
\text { pa }\end{array}$ & $\begin{array}{l}\text { Stryker } 90^{\circ} \text {, } \\
\text { pa }\end{array}$ & $\begin{array}{l}\text { aap } 180^{\circ} \text {, } \\
\text { ma }\end{array}$ & $\begin{array}{l}\text { aap } 90^{\circ} \text {, } \\
\text { ma }\end{array}$ & $\begin{array}{l}\text { aap } 180^{\circ}, \\
\text { pa }\end{array}$ & $\begin{array}{l}\text { aap } 90^{\circ}, \\
\text { pa }\end{array}$ \\
\hline $\begin{array}{l}\text { Stryker } 180^{\circ}, \\
\text { pa }\end{array}$ & & $<0.001$ & $<0.001$ & $<0.001$ & n.s. & $<0.001$ \\
\hline Stryker $90^{\circ}$, pa & & & $<0.001$ & n.s. & $<0.001$ & n.s. \\
\hline aap $180^{\circ}$, ma & & & & $<0.001$ & 0.007 & $<0.001$ \\
\hline aap $90^{\circ}, \mathrm{ma}$ & & & & & $<0.001$ & n.s. \\
\hline aap $180^{\circ}$, pa & & & & & & $<0.001$ \\
\hline
\end{tabular}

pa: poly-axial, ma: mono-axial, n.s.: $p>0.003$ 


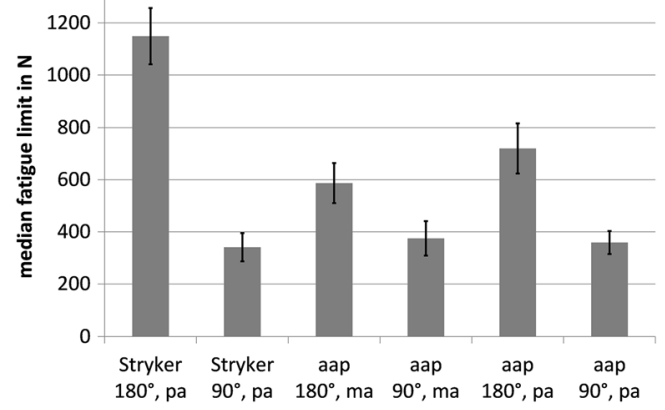

Fig. 4 Median (with SD) fatigue limit in $\mathrm{N}$ for the six groups

the systems' individual stiffnesses, the $180^{\circ}$ Stryker configuration demonstrated the highest stiffness, being significantly stiffer $(p<0.001)$ than any other system but the poly-axial $180^{\circ}$ aap system ( $p=0.06$; Fig. 3 and Table 2 ). No difference was observed between mono-axial and poly-axial screw fixation regarding the construct stiffness in the aap system $(\mathrm{p}=$ 0.69 for $90^{\circ}$ and $\mathrm{p}=0.19$ for $180^{\circ}$ ).

The cyclic fatigue tests revealed significant differences among the six groups for the median fatigue limits $(p<$ 0.001). For aap, Tukey's post hoc analysis demonstrated a higher MFL for the $180^{\circ}$ configurations than for the $90^{\circ}$ configurations but did not demonstrate differences between the mono- and poly-axial configurations (Fig. 4, Table 3).

Failure mechanism for all $90^{\circ}$ systems was a fatigue breakage of the posterolateral plate. The $180^{\circ}$ aap systems failed by breakage of the distal screws of the lateral plate, the $180^{\circ}$ Stryker systems additionally on the medial plate. In some cases additional breakage of the composite bone was observed at the location of the screw holes.

\section{Discussion}

Double plate osteosynthesis is the standard treatment for intercondylar or supracondylar distal humeral fractures [17] demonstrating good and reliable treatment outcome [18-20]. In this biomechanical study the two most common plate configurations (parallel and perpendicular) were compared with respect to the stiffness they provide for fracture fixation and their fatigue strength under cyclic loading. Parallel plating $\left(180^{\circ}\right)$ consistently demonstrated higher fracture fixation stiffness and higher median fatigue limit compared to perpendicular plating $\left(90^{\circ}\right)$. For the implants used in this study the use of poly-axial locking screws did not affect stiffness or fatigue compared to mono-axial locking screws.

For the biomechanical tests a setup was chosen which enabled testing of the distal humerus in an extension loading mode [12]. Therefore, the mechanical performance of the plating configuration was assessed in the most relevant physiological loading condition of the elbow joint [3]. Loads were physiologically distributed on the elbow joint $[12,13]$.

As expected from previous studies $[8,21-23]$ the $180^{\circ}$ parallel configurations demonstrated a higher stiffness than the $90^{\circ}$ perpendicular configurations for the axial loading mode. This biomechanical advantage of parallel plating, has been confirmed by good clinical results [24]. However, this biomechanical advantage in extension loading does not necessarily transfer to flexion loading mode as the bending moments in flexion interact differently with the plate configurations [14]. As the loads in extension are expected to be higher than in flexion [25], the extension configuration might be more relevant for the analysis of fixation stiffness as well as for the failure of fixation. Loads in varus and valgus direction are not introduced during controlled elbow flexion and extension but are rather due to unintended force applications, which should be avoided during early rehabilitation after fractures around the elbow. Furthermore, loads in other directions, e.g. anterior or posterior direction need to be compensated by muscular activity mainly resulting in compressive loading of the elbow joint. Nevertheless, the findings from our biomechanical study are limited to the extent that they focus on compressive loading during extension and lack the inclusion of torsion and moments from other loading situations.

In our biomechanical testing scenario, failure for the perpendicular configuration occurred as breakage of the posterolateral plate and can be explained by high bending forces acting on the posterolateral plate which resulted in stress concentration in the plate holes [26]. Failure for the parallel configuration occurred consistently at higher load levels and through breakage of the screws or the bone material
Table 3 Post hoc comparison of median fatigue limits for all individual groups

\begin{tabular}{|c|c|c|c|c|c|c|}
\hline & $\begin{array}{l}\text { Stryker } 180^{\circ}, \\
\text { pa }\end{array}$ & $\begin{array}{l}\text { Stryker } 90^{\circ} \text {, } \\
\text { pa }\end{array}$ & $\begin{array}{l}\text { aap } 180^{\circ} \text {, } \\
\text { ma }\end{array}$ & $\begin{array}{l}\text { aap } 90^{\circ} \text {, } \\
\text { ma }\end{array}$ & $\begin{array}{l}\text { aap } 180^{\circ} \text {, } \\
\text { pa }\end{array}$ & $\begin{array}{l}\text { aap } 90^{\circ}, \\
\text { pa }\end{array}$ \\
\hline $\begin{array}{l}\text { Stryker } 180^{\circ}, \\
\text { pa }\end{array}$ & & $<0.001$ & $<0.001$ & $<0.001$ & $<0.001$ & $<0.001$ \\
\hline Stryker $90^{\circ}$, pa & & & $<0.001$ & n.s. & $<0.001$ & n.s. \\
\hline aap $180^{\circ}$, ma & & & & $<0.001$ & 0.012 & $<0.001$ \\
\hline aap $90^{\circ}, \mathrm{ma}$ & & & & & $<0.001$ & n.s. \\
\hline aap $180^{\circ}$, pa & & & & & & $<0.001$ \\
\hline
\end{tabular}

pa: poly-axial, ma: mono-axial, n.s.: $p>0.05$ 
suggesting a more efficient load distribution in parallel plating. For all tested configurations the median fatigue limit for 250,000 loading cycles exceeded $340 \mathrm{~N}$. Loads occurring at the elbow during activities of daily living are about 0.3 to 0.5 times body weight [25], equivalent to $220 \mathrm{~N}$ to $370 \mathrm{~N}$ for a person of $75 \mathrm{~kg}$. Considering the fact that the elbow will only be loaded carefully during the first weeks of post-operative fracture care, the median fatigue limit appears to be sufficient for all plate configurations to endure the time for normal fracture healing. The values for stiffness and fatigue are in good agreement with results from previous studies on similar implant configurations [5, 14].

The design of recent locked plating systems provides the opportunity for poly-axial screw placement. While this enhances the ability to capture individual fracture fragments by placing the screws accordingly, it involves the risk of earlier screw loosening [27]. The findings from this study suggest that the poly-axial mechanism has no biomechanical disadvantages in terms of construct stiffness and fatigue failure. Previous studies even suggested that poly-axial locking mechanisms are more forgiving in terms of screw stability for deviation from correct screw inclination than fixed angle locking mechanisms [27].

As a limitation, dynamic testing was only performed in extension because this is the more challenging load application for the elbow joint [12]. However, the elbow joint also has to support a considerable amount of torsion which was not tested in the current study. Artificial bones were used instead of human bones due to our particular interest in the implant systems themselves and their mechanical performance. Thus, the test setup did not consider any soft tissue forces from tendons and ligaments which are thought to stabilize the fracture. It has to be considered that human bone, in particular osteoporotic bone may not be able to withstand the loads applied in this study and might result in failure at lower load levels due to bone failure or screw penetration. Furthermore, biological factors potentially affecting the biomechanical responses such as or individual healing response or comorbidities (e.g., smoking, obesity, or diabetes mellitus) which are associated with early loosening or breakage of implants cannot be considered in the biomechanical test setting [28]. Finally, only one singular fracture situation, the AO/OTA C2.3 fracture type was investigated representing a frequent and technically challenging type of complex intra-articular distal humeral fractures [29].

In conclusion, the tested anatomical plating systems provide sufficient mechanical stability for the fixation of complex distal humeral fractures. Consistently the parallel plate configurations demonstrated superior stiffness and fatigue performance. No differences in mechanical performance were found between poly- and mono-axial screw systems. Nevertheless, the clinical choice of the correct implant configuration needs to consider the individual fracture configuration, local soft tissue situation, and surgeon's preferences.

Acknowledgements Open access funding provided by Paracelsus Medical University. Patrick A. Varady and Christian von Rüden contributed equally to this work.

Publisher's Note Springer Nature remains neutral with regard to jurisdictional claims in published maps and institutional affiliations.

\section{Compliance with ethical standards}

Conflict of interest Stryker and aap provided financial support to the authors' institution for the biomechanical testing of the implants.

Ethical approval This article does not contain any studies with human participants or animals performed by any of the authors.

Open Access This article is distributed under the terms of the Creative Commons Attribution 4.0 International License (http:// creativecommons.org/licenses/by/4.0/), which permits unrestricted use, distribution, and reproduction in any medium, provided you give appropriate credit to the original author(s) and the source, provide a link to the Creative Commons license, and indicate if changes were made.

\section{References}

1. Bégué T (2014) Articular fractures of the distal humerus. Orthop Traumatol Surg Res 100(1 Suppl):S55-S63. doi:10.1016/j.otsr. 2013.11.002

2. Wang Y, Zhuo Q, Tang P et al (2013) Surgical interventions for treating distal humeral fractures in adults. Cochrane Database Syst Rev 1:CD009890. doi:10.1002/14651858.CD009890.pub2

3. Amis AA, Dowson D, Wright V (1980) Analysis of elbow forces due to high-speed forearm movements. J Biomech 13(10):825-831

4. Caravaggi P, Laratta JL, Yoon RS et al (2014) Internal fixation of the distal humerus: a comprehensive biomechanical study evaluating current fixation techniques. J Orthop Trauma 28(4):222-226. doi:10.1097/BOT.0b013e3182a6693f

5. Hungerer S, Wipf F, von Oldenburg G et al (2014) Complex distal humerus fractures-comparison of polyaxial locking and nonlocking screw configurations-a preliminary biomechanical study. J Orthop Trauma 28(3):130-136. doi:10.1097/BOT.0b013e31829d19a4

6. Lee J-K, Choi Y-S, Sim Y-S et al (2016) Dual plate fixation on distal third diaphyseal fracture of the humerus. Int Orthop. doi:10. 1007/s00264-016-3355-4

7. Li SH, Li ZH, Cai ZD et al (2011) Bilateral plate fixation for type C distal humerus fractures: experience at a single institution. Int Orthop 35(3):433-438. doi:10.1007/s00264-010-1011-y

8. Bogataj M, Kosel F, Norris R et al (2015) Biomechanical study of different plate configurations for distal humerus osteosynthesis. Med Biol Eng Comput 53(5):381-392. doi:10.1007/s11517-015$1247-1$

9. Atalar AC, Tunali O, Ersen A et al (2016) Biomechanical comparison of orthogonal versus parallel double plating systems in intraarticular distal humerus fractures. Acta Orthop Traumatol Turc. doi:10.1016/j.aott.2016.11.001

10. Taylor PA, Owen JR, Benfield CP et al (2016) Parallel plating of simulated distal humerus fractures demonstrates increased stiffness relative to orthogonal plating with a distal humerus locking plate 
system. J Orthop Trauma 30(4):e118-e122. doi:10.1097/BOT. 0000000000000477

11. Jayakumar P, Ring D (2015) A pitfall in fixation of distal humeral fractures with pre-contoured locking compression plate. Arch Bone Jt Surg 3(2):130-133

12. Schuster I, Korner J, Arzdorf M et al (2008) Mechanical comparison in cadaver specimens of three different 90-degree double-plate osteosyntheses for simulated C2-type distal humerus fractures with varying bone densities. J Orthop Trauma 22(2):113-120. doi:10. 1097/BOT.0b013e3181632cf8

13. Halls AA, Travill A (1964) Transmission of pressures across the elbow joint. Anat Rec 150:243-247

14. Penzkofer R, Hungerer S, Wipf F et al (2010) Anatomical plate configuration affects mechanical performance in distal humerus fractures. Clin Biomech (Bristol, Avon) 25(10):972-978. doi:10. 1016/j.clinbiomech.2010.07.005

15. Morrey BF, Sanchez-Sotelo J (eds) (2009) The elbow and its disorders, 4th edn. Elsevier, Philadelphia

16. Little RE (1981) Tables for estimating median fatigue limits. ASTM special technical publication, vol 731. ASTM, Philadelphia

17. Zalavras CG, McAllister ET, Singh A et al (2007) Operative treatment of intra-articular distal humerus fractures. Am J Orthop (Belle Mead NJ) 36(12 Suppl 2):8-12

18. Kumar S, Singh S, Kumar D et al (2015) Intercondylar humerus fracture- parallel plating and its results. J Clin Diagn Res 9(1): RC01-RC04. doi:10.7860/JCDR/2014/12137.5479

19. Lee SK, Kim KJ, Park KH et al (2014) A comparison between orthogonal and parallel plating methods for distal humerus fractures: a prospective randomized trial. Eur J Orthop Surg Traumatol 24(7):1123-1131. doi:10.1007/s00590-013-1286-y

20. Tian D, Jing J, Qian J et al (2013) Comparison of two different double-plate fixation methods with olecranon osteotomy for intercondylar fractures of the distal humeri of young adults. Exp Ther Med 6(1):147-151. doi:10.3892/etm.2013.1102
21. Arnander MW, Reeves A, MacLeod IA et al (2008) A biomechanical comparison of plate configuration in distal humerus fractures. $\mathrm{J}$ Orthop Trauma 22(5):332-336. doi:10.1097/BOT. 0b013e31816edbce

22. Kollias CM, Darcy SP, Reed JGR et al (2010) Distal humerus internal fixation: a biomechanical comparison of 90 degrees and parallel constructs. Am J Orthop (Belle Mead NJ) 39(9):440-444

23. Zalavras CG, Vercillo MT, Jun B-J et al (2011) Biomechanical evaluation of parallel versus orthogonal plate fixation of intraarticular distal humerus fractures. J Shoulder Elbow Surg 20(1): 12-20. doi:10.1016/j.jse.2010.08.005

24. Celli A, Donini MT, Minervini C (2008) The use of pre-contoured plates in the treatment of $\mathrm{C} 2-\mathrm{C} 3$ fractures of the distal humerus: clinical experience. Chir Organi Mov 91(2):57-64. doi:10.1007/ s12306-007-0022-3

25. An KN, Kwak BM, Chao EY et al (1984) Determination of muscle and joint forces: a new technique to solve the indeterminate problem. J Biomech Eng 106(4):364-367

26. Kudo T, Hara A, Iwase $\mathrm{H}$ et al (2016) Biomechanical properties of orthogonal plate configuration versus parallel plate configuration using the same locking plate system for intra-articular distal humeral fractures under radial or ulnar column axial load. Injury 47(10): 2071-2076. doi:10.1016/j.injury.2016.08.012

27. Lenz M, Wahl D, Gueorguiev B et al (2015) Concept of variable angle locking-evolution and mechanical evaluation of a recent technology. J Orthop Res 33(7):988-992. doi:10.1002/jor.22851

28. Claessen FMAP, Braun Y, Peters RM et al (2015) Plate and screw fixation of bicolumnar distal humerus fractures: factors associated with loosening or breakage of implants or nonunion. J Hand Surg [Am] 40(10):2045-2051.e2. doi:10.1016/j.jhsa.2015.07.009

29. McCarty LP, Ring D, Jupiter JB (2005) Management of distal humerus fractures. Am J Orthop (Belle Mead NJ) 34(9):430-438 